\title{
Proprioceptive deficits in Parkinson's disease: from clinical data to animal experimentation
}

\author{
Letícia Ribeiro ${ }^{1}$, Tadeu Mello e Souza ${ }^{1}$, Lisiane Bizarro ${ }^{1}$ and Alcyr Oliveira ${ }^{2}$ \\ 1 - Universidade Federal do Rio Grande do Sul, Porto Alegre, RS, Brazil. \\ 2 - Universidade Federal de Ciências da Saúde de Porto Alegre, Porto Alegre, RS, Brazil
}

\begin{abstract}
Parkinson's disease (PD) is characterized by the manifestation of akinesia, slowness to initiate movement, muscle rigidity, and tremors. However, recent evidence indicates that this pathology also causes alterations in proprioception. Disturbances in proprioceptive mechanisms directly affect postural control and the ability to calculate the velocity and amplitude of movement, suggesting that these alterations are related to the motor symptoms of PD. This article reviews the clinical data on these symptoms and presents evidence of a connection between proprioceptive deficits and the physiology of PD. The identification of proprioceptive impairments in different forms of Parkinsonism can provide valuable clues on the physiopathology of proprioception in idiopathic PD. Keywords: proprioception, Parkinson's disease, animal models of parkinsonism.
\end{abstract}

Received 11 November 2010; received in revised form 26 April 2011; accepted 13 May 2011. Available on line 10 October 2011

\section{Introduction}

Parkinson's disease (PD) is a progressive neurodegenerative disorder that affects dopaminergic neurons in the substantia nigra pars compacta (SNpc; Snider, Fahn, Isgreen, \& Cote, 1976). Since the first report of PD in 1817 , it has been characterized by clinical manifestations of akinesia, slowing of physical movement, muscle rigidity, tremors (Alexi et al., 2000) and proprioceptive impairment (Jacobs \& Horak, 2006; Vaugoyeau, Viel, Assaiante, Amblard, \& Azulay, 2007).

Proprioception is responsible for the perception of body position in space and whether members remain static or are moving (Jacobs \& Horak, 2006). A disruption in proprioceptive mechanisms may cause impairments in postural control, leading to limitations in the estimation of the amplitude and speed of movement. The involvement of proprioception in the maintenance of motor skills in normal subjects suggests that proprioceptive deficits may be linked to

Letícia Ribeiro and Lisiane Bizarro, Programa de PósGraduação em Psicologia, Departamento de Psicologia do Desenvolvimento e da Personalidade, Universidade Federal do Rio Grande do Sul, Brasil; Tadeu Mello e Souza, Departamento de Bioquímica, Universidade Federal do Rio Grande do Sul; Alcyr Oliveira, Departamento de Psicologia, Programa de Pós-Graduação em Ciências da Reabilitação, Universidade Federal de Ciências da Saúde de Porto Alegre, RS, Brasil. Correspondence regarding this article should be directed to Alcyr Oliveira, PhD. Phone: ++55-51-33038826. E-mail: alcyr@ufcspa.edu.br the motor symptoms of PD (Vaugoyeau et al., 2007).

Parkinson's disease patients show difficulties performing movements that rely on proprioceptive integration, such as requiring upper-limb movements or estimating position without vision (Klockgether, Borutta, Rapp, Spieker, \& Dichgans, 1995; Seiss, Praamstra, Hesse, \& Rickards, 2003). Performance in tasks that require reaching a target without visual perception of the forefinger or walking to a location without leg visibility is impaired in the initial stages of this disorder (Adamovich, Berkinblit, Hening, Sage, \& Poizner, 2001; Keijsers, Admiraal, Cools, Bloem, \& Gielen, 2005). These patients often present difficulty keeping the body still and an inability to use the legs to recover balance when having gait disturbances (Rocchi, Chiari, Cappello, Gross, \& Horak, 2004). These symptoms suggest the impaired capacity to integrate proprioceptive information to adjust movement and restore balance (Contreras-Vidal \& Gold, 2004; Jacobs \& Horak, 2006).

Despite contrary evidence (Dietz \& Duysens, 2000), sensorimotor abnormalities caused by PD have been suggested to not be the product of damage to peripheral proprioceptive receptors but rather a deficiency in cortical sensory integration (Seiss et al., 2003). The difficulty interpreting sensorial information appears to be related to the cortical degeneration of sensorimotor and premotor areas, which hinders adequate proprioceptive feedback, thus causing the patient to falsely estimate his position relative to his surroundings (Contreras-Vidal \& Gold, 2004; Jacobs \& Horak, 2006; Seiss et al., 2003). The 
present article explores the implication of deficits in the proprioceptive system by examining evidence that suggests a physiological basis for several symptoms of PD.

\section{Parkinson's disease characteristics}

Parkinson's disease affects $2.5 \%$ of the world's population and is the second most frequent neurodegenerative disorder that affects the elderly (Hattori, Kobayashi, Sasaki-Hatano, Sato, \& Mizuno, 2003). However, it also affects young individuals (Alexi et al., 2000). One of the hallmarks of PD is the progressive death of dopaminergic neurons in the SNpc, the cause of which is yet unknown. Studies have indicated a multifactorial origin for the disease that involves both genetic and environmental factors (Hattori et al., 2003). Mitochondrial dysfunction, oxidative stress, genetic alterations of parkin and $\alpha$-synuclein protein expression, and the consequent presence of Lewy bodies in SNpc neurons are some of the molecular mechanisms that promote PD (Hattori et al., 2003).

Neuronal loss of approximately $50 \%$ in the SNpc leads to dopaminergic depletion of approximately $80 \%$ in the striatum, one of the target structures of nigral projections. When neuron deterioration reaches such levels, compensation mechanisms are insufficient to contain deficits, leading to the manifestation of initial PD motor symptoms (Simola, Morelli, \& Carta, 2007).

Motor-skill disturbances in PD largely affect the patient's quality of life. These motor deficits appear during ordinary daily tasks such as walking, sitting, and moving members to reach objects. Adequate performance in all of these tasks requires proper integration between sensory inputs and motor responses, which essentially depend on proprioception (Varraine, Bonnard, \& Pailhous, 2002).

\section{Proprioception: definition and concept}

The term "proprioception" derives from the Latin word proprius, meaning "own." Sherrington initially used it to define sensorial processes involved in the consciousness of the spatial location of an individual, posture, and movement (Voight \& Cook, 2001). This mechanism is essential for establishing an appropriate relationship between space and the ability to move accordingly.

The control of posture and movement ultimately depends on the orchestrated feedback of muscle contraction, muscle stretching, and the corresponding response reflected in the spinal cord. Movement thus depends on the speed and precision with which mechanoreceptors located in muscle fibers signal these alterations (Voight \& Cook, 2001). Since the 1970s, however, researchers have suggested that the contribution of sensorial afferents cannot be excluded from proprioception (Goodwin, McCloskey, \&
Matthews, 1972; O'Suilleabhain, 2004; Vaugoyeau et al., 2007). Stimuli from the skin and articulation receptors may also contribute to the conscious judgment of kinetic and static activity (Goodwin et al., 1972; Vaugoyeau et al., 2007). The adequate functioning of these receptors as contributors to the proprioceptive system may be important for the sensorial perception of alterations found in PD patients (O'Suilleabhain, 2004; Snider et al., 1976).

\section{Sensorial alterations in PD and their implications for proprioception}

Parkinson's disease patients may manifest itching, tingling, and burning sensations or clumsiness of the arms and legs, symptoms collectively known as paresthesia (O'Suilleabhain, 2004). Few studies have investigated the presence of paresthesia in PD or systematically quantified the appearance, course, and magnitude of these symptoms (O'Suilleabhain, 2004). Quantitative sensorial studies in PD patients have shown that they have increased thresholds for tactile and thermal stimuli and a significant reduction in mechanical pain perception (Nolano et al., 2008; Tinazzi et al., 2008; Table 1). Some studies have suggested that sensorial alterations follow the course of the disease and tend to manifest along with other motor symptoms. Snider and colleagues (1976), however, stated that paresthesia emerges as an initial symptom of the disorder in approximately $20 \%$ of cases. A clinical survey of 101 patients diagnosed with PD revealed that $42 \%$ of the patients suffered from paresthesia (Snider et al., 1976). In a similar study involving 99 patients, $63 \%$ complained of these sensations, and the authors related their manifestation to the course of the disease (Shulman, Singer, Bean, \& Weiner, 1996). Koller (1984) studied 50 PD patients and reported that $20 \%$ suffered from a continuous form of paresthesia, whereas $18 \%$ complained of sporadic symptoms. Another report with a sample of 85 PD patients found that $70 \%$ complained of paresthesia, many of them specifically during the off periods of treatment with dopaminergic agonists (Gunal, Nurichalichi, Tuncer, Bekiroglu, \& Aktan, 2002). These results suggest that paresthesia is not a rare symptom. One study found that of 50 patients interviewed during the off period of dopamine agonist treatment, approximately $40 \%$ presented these symptoms. In this study, five subjects complained that the intensity of these symptoms in the off state was more disabling than the typical motor symptoms (Witjas et al., 2002).

Despite the importance of clinical surveys of PD, the lack of empirical studies that have focused exclusively on the presence, course, and magnitude of these symptoms hinders precise correlations between their manifestation and other crucial data involved in the development of PD. Early disease onset or prolonged 
Table 1. Sensory complaints in Parkinson's disease patients

\begin{tabular}{|c|c|c|c|}
\hline Reference/Year & Subjects & Methods & Results \\
\hline $\begin{array}{l}\text { Snider et al., } \\
1976\end{array}$ & 101 patients & Self-report and clinical evaluation & $43 \%$ suffered from paresthesia. \\
\hline $\begin{array}{l}\text { Shulman et al., } \\
1996\end{array}$ & $\begin{array}{l}100 \text { patients }+50 \\
\text { age-matched controls }\end{array}$ & Questionnaire & $\begin{array}{l}73 \% \text { of } \mathrm{PD} \text { patients had sensory } \\
\text { symptoms. } 44 \% \text { had internal } \\
\text { tremor. }\end{array}$ \\
\hline Koller, 1984 & 50 patients & Self-report & $\begin{array}{l}38 \% \text { had sensory complaints and } \\
\text { no objective sensory loss. Symp- } \\
\text { toms were frequently restricted to } \\
\text { the hemiparkinson side. }\end{array}$ \\
\hline $\begin{array}{l}\text { Gunal et al., } \\
2002\end{array}$ & 85 patients & $\begin{array}{l}\text { Survey based on self-report about the pres- } \\
\text { ence of paresthesias }\end{array}$ & $\begin{array}{l}\sim 40 \% \text { reported paresthesia, which } \\
\text { was more disabling than motor } \\
\text { symptoms in five patients. }\end{array}$ \\
\hline $\begin{array}{l}\text { Witjas et al., } \\
2002\end{array}$ & $\begin{array}{l}50 \text { patients in the } \\
\text { off-phase }\end{array}$ & $\begin{array}{l}\text { Questionnaire that used } 54 \text { yes-or-no ques- } \\
\text { tions about nonmotor fluctuations that occur } \\
\text { in the off-phase }\end{array}$ & $\begin{array}{l}100 \% \text { with at least one type of } \\
\text { nonmotor fluctuation (anxiety } \\
66 \% \text {; drenching sweats } 64 \% \text {; } \\
\text { slowness of thinking } 58 \% \text {; fatigue } \\
56 \% \text {; akathisia } 54 \% \text { ). }\end{array}$ \\
\hline $\begin{array}{l}\text { Nolano et al., } \\
2008\end{array}$ & $\begin{array}{l}18 \text { patients }+30 \text { age- } \\
\text { matched controls }\end{array}$ & $\begin{array}{l}\text { During the on-phase, patients were challenged } \\
\text { with tactile and thermal stimuli of the hands } \\
\text { and feet while electrophysiological signs } \\
\text { were recorded. Under local anesthesia, skin } \\
\text { punches were taken from the fingertip, thigh, } \\
\text { and distal leg. }\end{array}$ & $\begin{array}{l}\text { Evidence of increased tactile and } \\
\text { thermal thresholds with reduced } \\
\text { pain perception and significant } \\
\text { loss of epidermal nerve fibers } \\
\text { and Meissner corpuscles. Disease } \\
\text { severity correlated with Meissner } \\
\text { corpuscle loss and reduced pain } \\
\text { and thermal perception. }\end{array}$ \\
\hline
\end{tabular}

exposure to L-3,4-dihydroxyphenylalanine (L-DOPA) may be related to the presence and intensity of these manifestations (O’Suilleabhain, 2004).

Little is known about the neurocircuitry involved in the physiopathology of paresthesia in PD. Studies conducted to track detectable electrophysiological damage to the skin and nerve endings in PD patients revealed an absence of observable peripheral alterations (Koller, 1984; O’Suilleabhain, 2004). A study conducted in 26 elderly patients, however, concluded that $53 \%$ of the subjects presented electrophysiological abnormalities in nerve conduction velocity in the cervical spine, and $73 \%$ presented the same impairments in the lumbar spine (Lee \& Trojanowski, 2006). The absence of evidence of radiculopathy in other studies of PD patients, however, suggests that paresthesia may have other origins (O'Suilleabhain, 2004). Nerve conduction velocity studies, however, have failed to track large sensory endings and small fibers, which appears to be necessary to elucidate peripheral sensory alterations.
Based on morphological analyses of skin biopsies (Nolano et al., 2008), one study suggested peripheral deafferentation in PD, showing a significant loss of epidermal nerve fibers and Meissner corpuscles. Additional findings found increased branching, nerve sprouting, and vascular bed enlargement, which may be attributable to compensatory mechanisms (Duffau \& Capelle, 2001; Nolano et al., 2008). What remains unknown is the connection between this peripheral loss and dopamine denervation in the basal ganglia. Impairments in basal ganglia and thalamocorticalbasal ganglia circuitry might be the main cause of the sensorial problems observed in PD, the mechanisms for which are yet unknown (Tinazzi et al., 2008).

Stimuli applied to the skin generate responses in the basal ganglia, especially in the SNpc, which plays a crucial role in the modulation of sensorial processing in the thalamus (Bendrups \& McKenzie, 1974). Data from proprioception-related evoked potential studies revealed that sensorial potential triggered in the parietal cortex in PD patients is usually normal (Nakashima, 
Nitta, \& Takahashi, 1992), reinforcing the probable absence of damage to sensorial system conduction in PD patients and pointing to extrapyramidal alterations caused by dopamine depletion. In fact, dopaminergic agonists appear to reduce the intensity of paresthesia symptoms in most cases and have been adopted as a clinical treatment strategy (Nutt \& Carter, 1984).

Basal ganglia are essential for the automatic execution of previously learned motor responses and are responsible for the motor output that completes the circuit initiated by peripheral inputs (Marsden, 1982). The basal ganglia have recently been suggested to play a more influential role in this process because of their involvement in the modulation of peripheral inputs. An adequate motor response requires the full analysis of the conditions in which the organism finds itself (Abbruzzese \& Berardelli, 2003). Impaired integration of sensorial and proprioceptive receptor inputs may lead to an underestimation of the position of members or to a miscalculation of the necessary speed for an action, producing bradykinesia (Berardelli, Rothwell, Thompson, \& Hallett, 2001). Similarly, damage to the extrapyramidal system may lead to interpretation errors regarding the quantity of received sensory stimuli and cause the automatic and unconscious performance of unnecessary movements, suggesting dyskinesia (O’Suilleabhain, 2004).

\section{Experimental evidence of proprioceptive alterations in Parkinson's disease}

In 1975, a report showed that PD patients presented impairments in the proprioceptive feedback of peripheral muscle receptors (Tatton \& Lee, 1975). Since this first empirical evidence, several studies have sought to describe these deficits.

The loss of postural control is the symptom that most affects the quality of life in PD. A characteristic posture in which the forward position of the head and torso affects the ability to control other movements appears in more advanced stages of the disease, leading to impaired balance and falls (Keranen et al., 2003). Although some evidence indicates that cortical proprioceptive information processing is more critical for equilibrium control, the vestibular system exerts a fundamental role in this function, especially with regard to static equilibrium (Vaugoyeau et al., 2007). Through galvanic stimulation of the vestibular system in healthy elderly and PD patients during a body movement perception task, Pastor and colleagues found no difference between patients and controls regarding body movement change perception (Table 2). These results provide evidence that possible vestibular dysfunction is not the cause of postural control impairments in PD, reinforcing the role of proprioception (Pastor, Day, \& Marsden, 1993).
Studies that have focused on tracking proprioceptive deficits through postural control have demonstrated the extent of this damage in PD patients. By asking PD patients and controls to reach a target point while seated, Schenkman and collaborators (2001) found that PD patients had reduced control over the spine rotation that is needed for lengthwise movement, showing deficits in postural balance. When asked to stand on a unidirectional spinning platform with lateral disturbances, PD patients also showed significant difficulty stabilizing their posture (Vaugoyeau et al., 2007). Another study used a similar device and found a similar increase in the latency to reorganize posture in PD patients (De Nunzio, Nardone, \& Schieppati, 2007).

Postural difficulties also affect gait quality. Parkinson's disease may cause a decreased ability to use the lower limbs to recover equilibrium through compensatory steps (Jacobs \& Horak, 2006; Rocchi et al., 2004). Proprioceptive deficits may lead to an underestimation of body position, reducing movement amplitude (Berardelli et al., 2001). In order to verify balance capacity through adequate compensatory steps, PD patients were asked to stand on a mobile platform and move towards a target without leg visibility while the base of the device underwent lateral disturbances. The subjects made steps with a smaller amplitude than controls because of a failure of postural reorganization (Jacobs \& Horak, 2006). However, parkinsonian gait is also affected by proprioceptive lower limb deficits. Parkinson's disease patients may also present impairments in applied leg strength during movement. This might be attributable to changes in the threshold or bias of extensor load receptor function and occurs because of a loss of sensitivity of load receptors, which normally occurs with age but reaches pathological levels in PD. No evidence has revealed how nigrostriatal denervation may affect load receptor sensitivity (Dietz \& Duysens, 2000).

Interestingly, deep brain stimulation either of the subthalamic nucleus (STN) or globus pallidus interna (GPi) in PD patients initially decreases postural instability and gait disability, and performance declines further with time in STN-stimulated patients (St George, Nutt, Burchiel, \& Horak, 2010), These patients also gain weight or even become obese (Rieu et el., 2010), which indicates that adequate nutritional follow-up care might be needed in these patients. More importantly, there is evidence to suggest the involvement of higher order brain structures beyond possible peripheral disturbances and basal ganglia impairments in proprioceptive deficits in PD. In trials in which subjects had to reach a mobile target using either a joystick (Flowers, 1976) or their own hands without limb visibility (Jacobs \& Horak, 2006; Seiss et al., 2003) or were asked to estimate the amplitude of arm extension while it was passively flexed (Klockgether et al., 1995), PD patients tended to fail compared with healthy aged-matched controls. 
Table 2. Experimental evidence of proprioception impairments in Parkinson's disease

\begin{tabular}{|c|c|c|c|c|}
\hline Reference/Year & Subjects & Methods & On/Off status & Results \\
\hline Seiss et al., 2003 & $\begin{array}{l}\text { PD and } \\
\text { Huntington's } \\
\text { disease patients } \\
+ \text { controls; } n=8 \\
\text { per group }\end{array}$ & $\begin{array}{l}\text { Proprioception-related evoked } \\
\text { potential was assessed by } \\
\text { electroencephalogram. The } \\
\text { subject's forefinger was } \\
\text { passively moved vertically by } \\
\text { a robot arm with both flexion } \\
\text { and extension movements. }\end{array}$ & $\begin{array}{l}\text { On medication } \\
\text { during the } \\
\text { experiments }\end{array}$ & $\begin{array}{l}\text { Largely normal early } \\
\text { proprioception-related evoked } \\
\text { potential, but changes in the } \\
\text { cortical processing of signals in } \\
\text { both diseases. }\end{array}$ \\
\hline $\begin{array}{l}\text { Jacobs \& Horak, } \\
2006\end{array}$ & $\begin{array}{l}\text { PD patients }+ \\
\text { controls. } n=10 \\
\text { per group }\end{array}$ & $\begin{array}{l}\text { Subjects stood on a moveable } \\
\text { platform and were asked to } \\
\text { take forward compensatory } \\
\text { steps in response to backward } \\
\text { movements of the platform. } \\
\text { They were tested with and } \\
\text { without the possibility to see } \\
\text { the platform. }\end{array}$ & $\begin{array}{l}\text { Tests in the off- } \\
\text { phase and after } \\
1 \mathrm{~h} \text { in the } 1 \mathrm{~h} \\
\text { on-phase }\end{array}$ & $\begin{array}{l}\text { Patients exhibited shorter } \\
\text { compensatory steps than } \\
\text { controls and used visual input } \\
\text { to take longer compensatory } \\
\text { steps when a target was } \\
\text { provided. Vision did not help } \\
\text { in severe cases. Medication did } \\
\text { not consistently improve the } \\
\text { patients' compensatory steps. }\end{array}$ \\
\hline $\begin{array}{l}\text { Vaugoyeau et al., } \\
2007\end{array}$ & $\begin{array}{l}11 \text { PD patients }+ \\
10 \text { controls. }\end{array}$ & $\begin{array}{l}\text { Subjects stood on a motor- } \\
\text { driven rotating platform } \\
\text { with closed and opened } \\
\text { eyes in different trials while } \\
\text { the platform was rotated } \\
\text { sinusoidally in either the pitch } \\
\text { or roll direction, depending on } \\
\text { the subject's position on the } \\
\text { platform. The oscillations in } \\
\text { posture were recorded by head } \\
\text { and trunk movements. }\end{array}$ & $\begin{array}{l}\text { Tests during the } \\
\text { on-phase }\end{array}$ & $\begin{array}{l}\text { Patients showed impaired } \\
\text { postural orientation and } \\
\text { stabilization compared with } \\
\text { controls with and without } \\
\text { vision. PD subjects failed } \\
\text { to maintain postural control } \\
\text { without vision also when static. }\end{array}$ \\
\hline $\begin{array}{l}\text { Contreras-Vidal } \\
\& \text { Gold, } 2004\end{array}$ & $\begin{array}{l}11 \text { patients }+ \\
11 \text { age-matched } \\
\text { controls }+10 \\
\text { young controls }\end{array}$ & $\begin{array}{l}\text { After training trials, the } \\
\text { participants were asked to } \\
\text { draw a path to connect targets } \\
\text { through an electronic device. } \\
\text { The apparatus did not allow } \\
\text { them to see their hands while } \\
\text { drawing. }\end{array}$ & $\begin{array}{l}\text { Two patients } \\
\text { were tested in } \\
\text { the off-phase. } \\
\text { Nine patients } \\
\text { were tested in } \\
\text { the on-phase. }\end{array}$ & $\begin{array}{l}\text { PD patients performed more } \\
\text { poorly than the other two } \\
\text { groups, presenting more errors } \\
\text { when trying to find the target } \\
\text { and longer latencies to perform } \\
\text { the task. }\end{array}$ \\
\hline $\begin{array}{l}\text { Pastor et al., } \\
1993\end{array}$ & $\begin{array}{l}\text { Patients + age- } \\
\text { matched controls }\end{array}$ & $\begin{array}{l}\text { Subjects were placed in an } \\
\text { apparatus and slowly moved } \\
\text { while being exposed to } \\
\text { galvanic stimulation of the } \\
\text { vestibular system. }\end{array}$ & $\begin{array}{l}\text { Patients tested } \\
\text { in on- and off- } \\
\text { phases. }\end{array}$ & $\begin{array}{l}\text { No significant difference was } \\
\text { found between patients and } \\
\text { controls in the ability to detect } \\
\text { body movement without the use } \\
\text { of the vestibular system. }\end{array}$ \\
\hline $\begin{array}{l}\text { De Nunzio et al., } \\
2007\end{array}$ & $\begin{array}{l}19 \text { patients }+ \\
13 \text { age-matched } \\
\text { controls }\end{array}$ & $\begin{array}{l}\text { Participants stood on an } \\
\text { electronically controlled, } \\
\text { driven platform that was } \\
\text { periodically translated in } \\
\text { the horizontal plane. Body } \\
\text { segment oscillations verified } \\
\text { by stereophotogrammetry and } \\
\text { electromyogram were recorded } \\
\text { from the tibialis anterior and } \\
\text { soleus. The subjects were } \\
\text { tested with their eyes closed } \\
\text { and opened. }\end{array}$ & $\begin{array}{l}\text { Patients tested in } \\
\text { the on-phase. }\end{array}$ & $\begin{array}{l}\text { Patients showed increased } \\
\text { latencies to rebalance their } \\
\text { posture when the reference was } \\
\text { changed. This result suggests } \\
\text { an abnormality in reorganizing } \\
\text { the strategies to coordinate } \\
\text { body posture based on different } \\
\text { sensorial cues. }\end{array}$ \\
\hline
\end{tabular}


The inability to reach a target or to correctly estimate the amplitude of a movement applied to their own limbs without visual clues indicates that this illness can impair the mental representation of limb position, a resource that enables movement planning (ContrerasVidal \& Gold, 2004; Flowers, 1976; Jacobs \& Horak, 2006; Klockgether et al., 1995; Seiss et al., 2003). The mental representation of body and space is linked to cortical structures, especially the parietal, motor, and premotor cortices, which are responsible for the integration of peripheral proprioceptive and visual inputs involved in movement planning (Montoya, Campbell-Hope, Pemberton, \& Dunnett, 1991). The impairments observed in limb estimation tasks suggest a possible degenerative process in these cortical areas in PD (Jacobs \& Horak, 2006; Seiss et al., 2003; Toma et al., 1999). Altogether, this body of evidence strengthens the possibility that the origin of proprioceptive deficits in PD may be attributable to peripheral receptor damage or cortical degeneration through basal ganglia denervation. Additionally, there is evidence to indicate the involvement of not only the dopaminergic system because the central cholinesterase inhibitor donepezil was able to reduce falls in advanced PD patients (Chung, Lobb, Nutt, \& Horak, 2010).

Although some evidence indicates the peripheral deafferentation of sensory receptors (Nolano et al., 2008) and abnormal functioning of extensor load receptors in the legs (Dietz \& Duysens, 2000), most researchers believe that proprioceptive deficits in PD depend on cortical integration dysfunction of these impulses (Seiss et al., 2003). This idea is mainly reinforced by experimental data in animal models based on induced dopaminergic death in the basal ganglia (Meredith, Sonsalla, \& Chesselet, 2008; Simola et al., 2007), which is discussed in the following section.

\section{Proprioceptive deficits in animal models of Parkinson's disease}

Preclinical PD protocols were developed mainly by using rodents to reproduce dopaminergic neuronal loss. The primary adopted techniques include genetic manipulation and, more frequently, neurotoxininduced dopamine depletion (Meredith et al., 2008; Simola et al., 2007).

Unilateral 6-hydroxydopamine (6-OHDA) infusion into the medial forebrain bundle (MFB) in rodents is arguably the oldest and most widespread experimental model of PD (Simola et al., 2007). Such lesions impair posture and induce deficits in skilled reaching tasks (Henderson, Watson, Halliday, Heinemann, \& Gerlach, 2003; Miklyaeva et al., 1997; Montoya et al., 1991). Sprague Dawley rats lesioned unilaterally in the MFB and tested for postural control showed a significant tendency to curve their bodies to the contralateral side of the lesion while the head was preferably pointed to the ipsilateral side compared with controls (Henderson et al., 2003; Table 3).

Gait impairments have also been shown in animals with similar lesions. In a task in which animals are moved over a horizontal surface and forced to use their forelimbs to regain balance and body posture, animals normally produce compensatory steps. Researchers have reported that MFB-lesioned rats took fewer compensatory steps than controls (Chang, Wachtel, Young, \& Kang, 1999). Approximately 80\% dopamine depletion in the STR, a level that mimics early PD, is sufficient to affect an animal's ability to adjust posture through compensatory steps (Chang et al., 1999). This task is similar to tasks adopted in human experiments. Parkinson's disease patients fail in tasks that require postural and gait reorganization, and rats with 6-OHDA-induced MFB lesions present similar difficulties.

Unilateral 6-OHDA lesions of the nigrostriatal system also affect the sensory-motor skills of the paw that is contralateral to the encephalic lesion, leading the animal to use the ipsilateral paw more than the contralateral paw ( Montoya et al., 1991; Simola et al., 2007). Dopamine loss of 50\% in the SNpc induces these deficits. Rats tend to choose the ipsilateral paw to achieve their goals in tasks such as the staircase test, which demands excellent forelimb motor skills (Simola et al., 2007). The same preference for the ipsilateral paw has been reported in tasks in which rats are exposed to forced postural adjustments that require the use of their forelimbs. In a skilled reaching task with a movable platform, unilaterally lesioned Long-Evans rats failed to initiate postural adjustments of the limb controlled by the dopamine-depleted side. However, these unilateral behavioral effects can only be seen in partial lesions of the SNpc (Whishaw, Pellis, \& Gorny, 1992). Substantial $(\sim 95 \%)$ reductions of dopamine in the striatum may lead to sensory-motor skill damage in both forelimbs. This result may be attributable to compensatory effects of the dopamine system (Whishaw et al., 1992).

Preference for the ipsilateral paw was also observed in both the cylinder test and sticky tape test. In the cylinder test, the frequency of forelimb leaning on the walls is measured during exploratory behavior in a glass cylinder (Simola et al., 2007). The sticky tape test consists of sticking tape to the animal's forelimbs and recording the latency to touch and remove the tape. In both tasks, lesioned animals tend to show a preference for the paw on the same side of the lesion by leaning it on the walls or quickly removing the tape, suggesting proprioceptive deficits in the paw affected by the nigrostriatal lesion (Castaneda et al., 2005; Tillerson et al., 2001).

Approximately $5-10 \%$ of human PD cases are heritable (Meredith et al., 2008). Animal models 
Table 3. Proprioception deficits in animal models of Parkinsonism

\begin{tabular}{lllll}
\hline Reference/Year & Subjects & Dopamine lesion & Experiment & Results \\
\hline $\begin{array}{l}\text { Miklyaeva et al., } \\
1997\end{array}$ & $\begin{array}{l}\text { Female Long- } \\
\text { Evans rats }\end{array}$ & $\begin{array}{l}\text { Unilateral infusion } \\
\text { with 6-OHDA into } \\
\text { the nigrostriatal } \\
\text { bundle }\end{array}$ & $\begin{array}{l}\text { Animals were tested according } \\
\text { to their ability to use the } \\
\text { dopamine-depleted side } \\
\text { rather than the normal limb } \\
\text { in tasks that required postural } \\
\text { adjustment. }\end{array}$ & $\begin{array}{l}\text { Animals were able to } \\
\text { support their posture over } \\
\text { the apparatus but failed to } \\
\text { initiate postural adjustments } \\
\text { of the dopamine-depleted } \\
\text { limb. }\end{array}$ \\
$\begin{array}{l}\text { Henderson et al., } \\
2003\end{array}$ & $\begin{array}{l}\text { Female } \\
\text { Sprague } \\
\text { Dawley rats }\end{array}$ & $\begin{array}{l}\text { Unilateral infusion } \\
\text { of 6-OHDA into the } \\
\text { medial forebrain } \\
\text { bundle }\end{array}$ & $\begin{array}{l}\text { Evaluation of head position and } \\
\text { curling body biases and tactile } \\
\text { vibrissae stimulation. }\end{array}$ & $\begin{array}{l}\text { Lesioned rats preferred the } \\
\text { contralateral side to curve } \\
\text { the body during postural } \\
\text { testing and ipsilateral side to } \\
\text { point the head during head } \\
\text { position evaluation. }\end{array}$ \\
\end{tabular}
$\begin{array}{ll}\text { Castaneda et al., } & \text { Male Fischer } \\ 2005 & \text { rats }\end{array}$

Chang et al., Male Wistar 1999

\begin{abstract}
Unilateral infusion of 6-OHDA into the medial forebrain bundle + grafts of into the denervated striatum
\end{abstract}

Unilateral infusion of 6-OHDA into the medial forebrain bundle
Somatosensory neglect (sticky-tape task), skilled reaching (staircase test), and apomorphine-induced rotation.

Rats were held by the experimenter. The experimenter fixed the hindlimbs with one hand and fixed the forelimbs with the other hand. The rats were moved slowly sideways in both the forehand and backhand positions. The number of adjusting steps in both directions and with both paws was counted.

During a period of $5 \mathrm{~min}$, the animals were placed in a round transparent cylinder. Their rearing and leaning behavior were scored, and the percentage of simultaneous and asymmetric leans of the paws on the walls of the glass was recorded.
Recovered motor function promoted by tissue transplantation.

\author{
Compared with controls, \\ lesioned rats $(\sim 80 \%$ \\ of lesion) made fewer \\ compensatory steps and had \\ longer latencies to adjust \\ their steps to rebalance the \\ initial posture. Animals with \\ lesions smaller than $80 \%$ \\ showed no deficits in this \\ task. \\ Dopamine depletion of \\ $\sim 80 \%$ in the striatum caused \\ ipsilateral preference rather \\ than the use of contralateral \\ paws to lean during \\ exploratory behavior.
}

based on genetic manipulation aim to reproduce the dysfunction found in some cases of PD. These studies utilize mutations in parkin, DJ-1, PINK1, $\alpha$-synuclein, LRRK2, and ATP13A2) (Lee \& Trojanowski, 2006). Mice with DJ-1 mutations usually present classic motor disturbances at approximately 11 months of age. Proprioception, however, was reported to affect animals within 5 months. When submitted to the sticky tape test, these mice exhibited an increase in the latency to remove the tape from the paws compared with controls (Meredith et al., 2008). This earlier manifestation of proprioceptive deficits compared with other motor impairments indicates that proprioception may be damaged prior to the manifestation of other symptoms (Snider et al., 1976).

Animal models have provided evidence of the neurocircuitry involved in the pathophysiological mechanisms of proprioceptive damage in PD. Dopaminergic depletion in the basal ganglia helped researchers glimpse the complex network of these structures and the manifestation of proprioceptive loss. The observation of similar gait and postural impairments in nigrostriatal dopamine-depleted subjects reinforces the hypothesis of encephalic proprioceptive loss rather than peripheral damage. What has not yet been addressed is whether the nigral DA loss is involved in peripheral deafferentation. 


\section{Cortical degeneration and proprioception deficits in Parkinson's disease}

Proprioception is a basic condition for planning adequate motor responses that relies on the involvement of premotor and motor cortices. Therefore, dopamine rising from nigrostriatal pathway modulates striatal neurons that regulate the function of the cortical motor area. Dense projections from the primary somatosensory cortex (S1) to the primary motor cortex (M1) reinforce the assumption that a motor cortical mechanism plays a role in proprioceptive modulation (Jacobs \& Horak, 2006). Neuroanatomical and electrophysiological findings reported efferent pathways from these two cortices to the putamen, the region most affected by dopaminergic depletion in PD. The putamen promotes subsequent changes in the information flux to the globus pallidus, another structure that plays a crucial role in the motor disturbances seen in PD (Flaherty \& Graybiel, 1991). Chemical alterations in this pathway followed by dopamine depletion affect the way peripheral proprioceptive afferents are interpreted, possibly causing disturbances in the ability to correctly estimate member position (Jacobs \& Horak, 2006).

Peripheral (tendon) stimulation in PD patients reduces the activation of contralateral somatosensory and premotor lateral cortices, in addition to altering the contralateral posterior cingulate cortex, bilateral prefrontal cortex, and basal ganglia contralateral to the peripheral stimulation (Boecker et al., 1999). Therefore, altered sensory processing might contribute to the motor deficits observed in PD.

Recent studies have shown that a complex interaction exists between the pathways that link cortical regions, the basal ganglia, and the thalamus. The supplementary motor area (SMA) might contribute to proprioceptive loss in PD (Jacobs \& Horak, 2006; Seiss et al., 2003). The SMA is a part of the premotor cortex (area 6) that receives proprioceptive and visual afferents from the posterior parietal cortex (areas 5 and 7) and sends descending corticospinal tract projections. This region is considered an indispensable junction for body position perception to understand the requested movement and how it will be performed (Toma et al., 1999). The SMA also likely supports highly abstract visuospatial computations (Leek \& Johnston, 2009).

The SMA receives a rich dopaminergic innervation, and a degeneration of this region is observed in the advanced stages of PD (Braak et al., 2002). This area is overactive in dyskinetic patients with $\mathrm{PD}$ and might play a central role in the development of dyskinesia induced by dopaminergic stimulation (Bezard, Brotchie, \& Gross, 2001). Indeed, in a positron emission tomography study of patients with dyskinetic PD, the degree of overactivation of the SMA, motor cortical areas, and the basal ganglia correlated with the severity of dyskinesia
(Brooks, Piccini, Turjanski, \& Samuel, 2000). Moreover, dyskinetic patients showed overactivity of motor and premotor areas, including the SMA, compared with nondyskinetic patients in a single-photon emission computed tomography study (Rascol et al., 1998). Further research is needed to elucidate the interaction between the proprioceptive system and sensorimotor system in the planning and execution of movement.

\section{Final considerations}

Proprioceptive loss is not strictly considered a symptom but rather a sign of PD because of its conscious complaint in PD patients. The difficulty of perceiving these deficiencies impairs clinical investigation. Therefore, lack of awareness of the problem and compensatory psychological mechanisms may help patients compensate for mild proprioceptive deficits when executing movement. These occurrences may lead to an underestimation of the presence, prevalence, and magnitude of these alterations.

The involvement of proprioception in $\mathrm{PD}$ is important and requires additional exploration to help patients overcome their limitations. Exercise and other physio- and psychotherapeutic strategies may improve proprioception while helping patients deal with their symptoms. The testing of new PD treatment drugs may also improve symptom perception by focusing on proprioception. According to recent evidence of peripheral deafferentation in PD, more studies are necessary to elucidate the magnitude, prevalence, and course of this damage. The relationship between peripheral deafferentation and nigral dopamine loss also needs to be revealed. Dopaminergic impairment in the basal ganglia may also be involved in other neurotransmitter imbalance, such as that involved in nociception, thermal perception, and postural control (Tinazzi et al., 2008). The complex mechanism that leads to this encephalic chemical imbalance of peripheral receptors has yet to be discovered.

Proprioception may be a key to understanding the progression of motor disease pathology. Therefore, studies of proprioceptive changes may help understand the course of proprioceptive alterations and develop strategies that minimize their impact on other systems and diminish the severity of PD symptoms.

\section{References}

Abbruzzese, G., \& Berardelli, A. (2003). Sensorimotor integration in movement disorders. Movement Disorder, 18, 231-240.

Adamovich, S. V., Berkinblit, M. B., Hening, W., Sage, J., \& Poizner, H. (2001). The interaction of visual and proprioceptive inputs in pointing to actual and remembered targets in Parkinson's disease. Neuroscience, 104, 1027-1041.

Alexi ,T., Borlongan, C.V., Faull, R.L., Williams, C.E., Clark, R.G., Gluckman, P.D., \& Hughes, P.E. (2000) Neuroprotective strategies for basal ganglia degeneration: Parkinson's and Huntington's diseases. Progress in Neurobiolology, 60, 409-470. 
Bendrups, A. P., \& McKenzie, J. S. (1974). Suppression of extralemniscal thalamic unit responses by substantia nigra stimulation. Brain Research, 80, 131-134.

Berardelli, A., Rothwell, J. C., Thompson, P. D., \& Hallett, M. (2001). Pathophysiology of bradykinesia in Parkinson's disease. Brain, 124, 2131-2146.

Bezard, E., Brotchie, J. M., \& Gross, C. E. (2001). Pathophysiology of levodopa-induced dyskinesia: potential for new therapies. Nature Review Neuroscience, 2, 577-588.

Boecker, H., Ceballos-Baumann, A., Bartenstein, P., Weindl, A., Siebner, H. R., Fassbender, Conrad, B. (1999). Sensory processing in Parkinson's and Huntington's disease: investigations with 3D H(2)(15)O-PET. Brain, 122, 1651-1665.

Braak, H., Del Tredici, K., Bratzke, H., Hamm-Clement, J., Sandmann-Keil, D., \& Rub, U. (2002). Staging of the intracerebral inclusion body pathology associated with idiopathic Parkinson's disease (preclinical and clinical stages). Journal of Neurology, 249 (Suppl 3), III/1-5.

Brooks, D. J., Piccini, P., Turjanski, N., \& Samuel, M. (2000). Neuroimaging of dyskinesia. Annals of Neurology, 47(4 Suppl 1), S154-158; discussion S158-159.

Castaneda, E., Fleming, S., Paquette, M. A., Boat, K., Moffett, J., Stachowiak, E. K., Stachowiak, M.K. (2005). Assessment of recovery in the hemiparkinson rat: drug-induced rotation is inadequate. Physiology and Behavior, 84, 525-535.

Chang, J. W., Wachtel, S. R., Young, D., \& Kang, U. J. (1999). Biochemical and anatomical characterization of forepaw adjusting steps in rat models of Parkinson's disease: studies on medial forebrain bundle and striatal lesions. Neuroscience, 88, 617-628.

Chung, K. A., Lobb, B. M., Nutt, J. G., \& Horak, F. B. (2010). Effects of a central cholinesterase inhibitor on reducing falls in Parkinson disease. Neurology, 75, 1263-1269.

Contreras-Vidal, J. L., \& Gold, D. R. (2004). Dynamic estimation of hand position is abnormal in Parkinson's disease. Parkinsonism \& Related Disorders, 10, 501-506.

De Nunzio, A. M., Nardone, A., \& Schieppati, M. (2007). The control of equilibrium in Parkinson's disease patients: delayed adaptation of balancing strategy to shifts in sensory set during a dynamic task. Brain Research Bulletin, 74, 258-270.

Dietz, V., \& Duysens, J. (2000). Significance of load receptor input during locomotion: a review. Gait Posture, 11, 102-110.

Duffau, H., \& Capelle, L. (2001). [Functional recuperation following lesions of the primary somatosensory fields. Study of compensatory mechanisms]. Neurochirurgie, 47, 557-563.

Flaherty, A. W., \& Graybiel, A. M. (1991). Corticostriatal transformations in the primate somatosensory system. Projections from physiologically mapped body-part representations. Journal of Neurophysiology, 66, 1249-1263.

Flowers, K. A. (1976). Visual "closed-loop" and "open-loop" characteristics of voluntary movement in patients with Parkinsonism and intention tremor. Brain, 99, 269-310.

Goodwin, G. M., McCloskey, D. I., \& Matthews, P. B. (1972). The contribution of muscle afferents to kinaesthesia shown by vibration induced illusions of movement and by the effects of paralysing joint afferents. Brain, 95, 705-748.

Gunal, D. I., Nurichalichi, K., Tuncer, N., Bekiroglu, N., \& Aktan, S. (2002). The clinical profile of nonmotor fluctuations in Parkinson's disease patients. Canadian Journal of Neurological Science, 29, 61-64.

Hattori, N., Kobayashi, H., Sasaki-Hatano, Y., Sato, K., \& Mizuno, Y. (2003). Familial Parkinson's disease: a hint to elucidate the mechanisms of nigral degeneration. Journal of Neurology, 250 (Suppl 3), III2-10.

Henderson, J. M., Watson, S., Halliday, G. M., Heinemann, T., \& Gerlach, M. (2003). Relationships between various behavioural abnormalities and nigrostriatal dopamine depletion in the unilateral 6-OHDA-lesioned rat. Behavior Brain Research, 139, 105-113.

Jacobs, J. V., \& Horak, F. B. (2006). Abnormal proprioceptive-motor integration contributes to hypometric postural responses of subjects with Parkinson's disease. Neuroscience, 141, 999-1009.

Keijsers, N. L., Admiraal, M. A., Cools, A. R., Bloem, B. R., \& Gielen, C. C. (2005). Differential progression of proprioceptive and visual information processing deficits in Parkinson's disease. The European Journal of Neuroscience, 21, 239-248.

Keranen, T., Kaakkola, S., Sotaniemi, K., Laulumaa, V., Haapaniemi, T., Jolma, T., Takala, A.(2003). Economic burden and quality of life impairment increase with severity of PD. Parkinsonism \& Related
Disorders, 9, 163-168.

Klockgether, T., Borutta, M., Rapp, H., Spieker, S., \& Dichgans, J. (1995). A defect of kinesthesia in Parkinson's disease. Movement Disorder, 10, 460-465.

Koller, W. C. (1984). Sensory symptoms in Parkinson's disease. Neurology, 34, 957-959.

Lee, V. M., \& Trojanowski, J. Q. (2006). Mechanisms of Parkinson's disease linked to pathological alpha-synuclein: new targets for drug discovery. Neuron, 52, 33-38.

Leek, E. C., \& Johnston, S. J. (2009). Functional specialization in the supplementary motor complex. Nature Review of Neuroscience. 10,78 ; author reply 78 .

Marsden, C. D. (1982). The mysterious motor function of the basal ganglia: the Robert Wartenberg Lecture. Neurology, 32, 514-539.

Meredith, G. E., Sonsalla, P. K., \& Chesselet, M. F. (2008). Animal models of Parkinson's disease progression. Acta Neuropathologica, $115,385-398$

Miklyaeva, E. I., Woodward, N. C., Nikiforov, E. G., Tompkins, G. J., Klassen, F., Ioffe, M. E., Whishaw, I.Q. (1997). The ground reaction forces of postural adjustments during skilled reaching in unilateral dopamine-depleted hemiparkinson rats. Behavioural Brain Research, 88, 143-152.

Montoya, C. P., Campbell-Hope, L. J., Pemberton, K. D., \& Dunnett, S. B. (1991). The "staircase test": a measure of independent forelimb reaching and grasping abilities in rats. Journal of Neuroscience Methods, 36, 219-228

Nakashima, K., Nitta, T., \& Takahashi, K. (1992). Recovery functions of somatosensory evoked potentials in parkinsonian patients. Journal of Neurology Science, 108, 24-31.

Nolano, M., Provitera, V., Estraneo, A., Selim, M. M., Caporaso, G., Stancanelli, A., Santoro, L. (2008). Sensory deficit in Parkinson's disease: evidence of a cutaneous denervation. Brain, 131, 1903-1911.

Nutt, J. G., \& Carter, J. H. (1984). Sensory symptoms in parkinsonism related to central dopaminergic function. Lancet, 2, 456-457.

O'Suilleabhain, P. (2004). Sensory symptoms and sensorimotor distortion Parkinson's disease. Washington D.C.: CRC Press.

Pastor, M. A., Day, B. L., \& Marsden, C. D. (1993). Vestibular induced postural responses in Parkinson's disease. Brain, 116, 1177-1190.

Rascol, O., Sabatini, U., Brefel, C., Fabre, N., Rai, S., Senard, J. M.,... Cholet, F. (1998). Cortical motor overactivation in parkinsonian patients with L-dopa-induced peak-dose dyskinesia. Brain, 121, 527-533.

Rieu, I., Boirie, Y., Morio, B., Derost, P., Ulla, M., Marques, A. Durif, F. (2010). [The Idiopathic Parkinson's disease: A metabolic disease?]. Revue Neurologique (Paris), 166, 822-828.

Rocchi, L., Chiari, L., Cappello, A., Gross, A., \& Horak, F. B. (2004). Comparison between subthalamic nucleus and globus pallidus internus stimulation for postural performance in Parkinson's disease. Gait Posture, 19, 172-183.

Schenkman, M. L., Clark, K., Xie, T., Kuchibhatla, M., Shinberg, M., \& Ray, L. (2001). Spinal movement and performance of a standing reach task in participants with and without Parkinson disease. Physical Therapy, 81, 1400-1411.

Seiss, E., Praamstra, P., Hesse, C. W., \& Rickards, H. (2003). Proprioceptive sensory function in Parkinson's disease and Huntington's disease: evidence from proprioception-related EEG potentials. Experimental Brain Research, 148, 308-319.

Shulman, L. M., Singer, C., Bean, J. A., \& Weiner, W. J. (1996). Internal tremor in patients with Parkinson's disease. Movement Disorder, 11, 3-7.

Simola, N., Morelli, M., \& Carta, A. R. (2007). The 6-hydroxydopamine model of Parkinson's disease. Neurotox Research, 11, 151-167.

Snider, S. R., Fahn, S., Isgreen, W. P., \& Cote, L. J. (1976). Primary sensory symptoms in parkinsonism. Neurology, 26, 423-429.

St George, R. J., Nutt, J. G., Burchiel, K. J., \& Horak, F. B. (2010). A meta-regression of the long-term effects of deep brain stimulation on balance and gait in PD. Neurology, 75, 1292-1299.

Tatton, W. G., \& Lee, R. G. (1975). Evidence for abnormal long-loop reflexes in rigid Parkinsonian patients. Brain Research, 100, 671-676.

Tillerson, J. L., Cohen, A. D., Philhower, J., Miller, G. W., Zigmond, M. J., \& Schallert, T. (2001). Forced limb-use effects on the behavioral and neurochemical effects of 6-hydroxydopamine. Journal of Neuroscience, 21, 4427-4435.

Tinazzi, M., Del Vesco, C., Defazio, G., Fincati, E., Smania, N., Moretto, G., Valeriani, M.(2008). Abnormal processing of the nociceptive input in Parkinson's disease: a study with $\mathrm{CO} 2$ laser 
evoked potentials. Pain, 136, 117-124.

Toma, K., Honda, M., Hanakawa, T., Okada, T., Fukuyama, H., Ikeda, A., Shibasaki, H. (1999). Activities of the primary and supplementary motor areas increase in preparation and execution of voluntary muscle relaxation: an event-related fMRI study. Journal of Neuroscience, 19, 3527-3534.

Varraine, E., Bonnard, M., \& Pailhous, J. (2002). Interaction between different sensory cues in the control of human gait. Experimental Brain Research, 142, 374-384.

Vaugoyeau, M., Viel, S., Assaiante, C., Amblard, B., \& Azulay, J. P. (2007). Impaired vertical postural control and proprioceptive integration deficits in Parkinson's disease. Neuroscience, 146, 852-863.

Voight, M. I., \& Cook, G. (2001). Impaired neuromuscular control: reactive neuromuscular training. In W. E. Prentice \& M. I. Voight (Eds.), Techniques in musculoskeletal rehabilitation (pp. 213-240). New York: McGraw-Hill.

Whishaw, I. Q., Pellis, S. M., \& Gorny, B. P. (1992). Skilled reaching in rats and humans: evidence for parallel development or homology. Behavioural Brain Research, 47, 59-70.

Witjas, T., Kaphan, E., Azulay, J. P., Blin, O., Ceccaldi, M., Pouget, J., Chérif, A.A. (2002). Nonmotor fluctuations in Parkinson's disease: frequent and disabling. Neurology, 59, 408-413. 